\title{
New Regulations on Notified Bodies and Conformity Assessment of High- Risk Medical Devices in Europe: Impact on Clinical Investigation from an Industry Perspective
}

\section{Wenche C. Groennvold}

Master of Science Clinical Research, University of Liverpool, Liverpool L69 3BX, United Kingdom

\begin{abstract}
Background: Proposals to a more rigorous medical device regulation concerning Notified Bodies and clinical evidence are met with controversies. The regulatory revision will not only endeavor improvement of patient safety and product quality, but is expected to have a direct impact on manufacturers bygeneratinghigher costs, longer processes to gather a CE mark and increased requirements for clinical evidence. Despite that industry recognizes a need for regulatory improvements, there are uncertainties about the estimated impact the regulatory changes have on European manufacturers.
\end{abstract}

Aim: To determine the impact the new regulations on Notified Bodies and conformity assessment have on clinical investigation of implantable medical devicesin Europe.

Methods: Data regarding information to 5 regulatory changes and their impact on different factors of clinical investigation were collected from 22 clinical research specialists working for manufacturers of implantable medical devices. The datawere collected through a cross-sectional, quantitative, descriptive survey and analyzed.

Results: It was determined that burden on costs and resources would be affected the most, while innovations and product development would be negatively affected. Additionally, product quality and patient safety would benefit minimally from the proposed regulatory changes.

Conclusion: The results obtained are in contrast to the intended aims of the proposed revisions. The proposed regulations may introduce economic and organizational challenges to manufacturers in Europe, particularly when considering the small- and-medium-sized enterprises. It is moreover debatable whether the goal of strengthening patient safety and allowing for rapid and cost-efficient market access for innovative products will be reached.

\section{Notification}

On June 19. 2015, the European Council published its proposal to the new European Union Medical Device Regulation[1].

On October 5. 2015, the Ministers of the EU countries agreed on a general approach on the medical devices package. This agreement is a major step towards the adoption of new regulations and serves as a basis for the discussion between the European Parliament, The European Council and the European Commission [2].

On June 13. 2016, the Ministers of the EU released the consolidated version of the New Medical Device Regulation [3].

The above-mentioned notifications were published after this study started, and the survey in this study is therefore based on the previous proposals from the European Commission and European Parliament. The European Councils' proposal and the consolidated version have been considered, and the context of this work continues to be relevant.

\section{Introduction}

The challenges of regulating medical device manufacturing sufficiently have been revealed by uncovering medical devices at the market that do not fulfill safety criteria to ensure patient protection and has led to patient harm and deaths $[4,5]$.

Manufacturers of medical devices in the European Union (plus Norway, Switzerland, Iceland and Liechtenstein) are obliged to ensure a product is designed and manufactured in accordance with applicable wenche@linkmedical.no regulations and requirements to place it on the European Union Market. The European system regulating high-risk medical devices entering the market is based on demonstrating product performance and safety to receive Conformitèe Européenne(CE) market certification [6]. All high-risk products are conformity assessed by a Notified Body (NB). NBs are organizations within Europe that have been designated by the Member States of the European Union to assess whether a product meets EU safety and performance requirements, necessary to obtain $\mathrm{CE}$ certification. Assessments can include calibration, testing, certification and inspection activities [7].

Current regulations are based on Directives. However, defining the directives is the responsibility of each Member State, and the directives are inconsistently interpreted. These inconsistencies result in high variances in depth and quality of NBs assessment of manufacturers' clinical evaluations and investigations. Further, designation and monitoring of NBs by regulatory authorities vary between countries and have been applied based on local voluntariness, rather than because of an EU requirement [8].

"Corresponding Author: Wenche C. Groennvold, Master of Science Clinical Research, University of Liverpool, Liverpool L69 3BX, United Kingdom; E-mail:

Citation: Groennvold WC (2017) New Regulations on Notified Bodies and Conformity Assessment of High-Risk Medical Devices in Europe: Impact on Clinical Investigation from an Industry Perspective. Int J Clin Res Trials 2: 115 doi: https://doi.org/10.15344/2456-8007/2017/115

Copyright: (c) 2017 Groennvold. This is an open-access article distributed under the terms of the Creative Commons Attribution License, which permits unrestricted use, distribution, and reproduction in any medium, provided the original author and source are credited. 
Citation: Groennvold WC (2017) New Regulations on Notified Bodies and Conformity Assessment of High-Risk Medical Devices in Europe: Impact on Clinical Investigation from an Industry Perspective. Int J Clin Res Trials 2: 115. doi: https://doi.org/10.15344/2456-8007/2017/115

Page 2 of 13

This procedure introduces concerns to trust conformity assessments in EU and whether provided documentation is sufficient to determine safety and performance as claimed by the manufacturer $[4,9,8]$.

In 2012, the European Commission (EC) published a proposal to introduce a new regulatory framework replacing existing medical device directives. In fall of 2013, the European Parliament (EP) amended the proposal to be more rigorous and in June 2015 the European Council (ECO) presented its amendments based on the two formers. Finally, in June 2016 the consolidated version of the new Medical Device Regulation was published [10, 11,2, 3].

In the dialogue about a regulatory agreement is an entirely new approach to previous regulation of NBs and conformity assessment processes (CAP) included. The focus has been tightened standards to the obligations of NBs when conformity assessing high-risk devices, for instance in the requirement of qualified employees. This tightening resulted in among others parts of the proposal being implemented to regulation " $(E U)$ No. 920/2013", as well as the "Commission Recommendation (of 24 September 2014)" on the audits and assessments performed by NBs in the field of medical devices. They comprise regulations pertaining designation and supervision of NBs by competent authorities and recommendations to audits and assessments of manufacturers $[6,12]$.

The publicized proposals have been met with controversies and raise discussions regarding their effect on involved stake holders. Several of the potential changes to NBs legislation directly affect manufacturers of implantable medical devices (IMD). The effect of such changes introduces advantages to manufacturers, such as more competent NBs and safer devices on the market. Contrary, it may result in too bureaucratic and lengthy conformity assessment procedures, increased governmental supervision, enhanced control of manufacturers through i.e. unscheduled audits, more transparency, and increased complexity without improving patient safety and requirement of more intensive clinical investigations. However, there remains a significant gap in knowledge to the proposed regulatory frameworks' impact on clinical investigations of implantable medical devices classified as high-risk devices $[13,14]$. There are few information sources available. NBs use heterogeneous methods in the CAP, and reports from assessments are not accessible to the public. Moreover, the lack of transparency in the clinical evidence dossier submitted to gain CE-mark, as well as by which NB the device was approved, limits the ability to evaluate proposed regulations' impact on clinical investigation of IMDs as it can only be speculative at best [15].
This study aim to examine and analyze the perception of manufacturers of IMDs about the impact the regulatory framework on NBs and conformity assessment will have on clinical investigation. A suggested increase in costs to services provided by NBs and increased demand for clinical investigation might reduce applications for market approval. Moreover, there are concerns regarding the sustainability of the many small-and-medium-sized manufacturers of high-risk devices in Europe. These companies perceivably do not have the capital to conduct clinical investigations when criteria's for demonstrating and proving equivalence gets stricter and they might not be able to meet regulatory and methodological requirements. A required increased level of clinical evidence could create resource barriers in the form of finance and time to bringing new products to the European market, thus further influencing patient access to new technology $[16,17]$.

\section{Background and Literature Review}

\section{Current regulations}

The core EU regulatory framework related to safety and performance of implantable medical devices (IMDs) consists of two directives [18]:

- Council Directive 90/385/EEC on Active Implantable Medical Devices (AIMDD)(1990)

- Council Directive 93/42/EEC on Medical Devices (MDD)(1993)

The aim of the Directives is to ensure protection of human health and safety at a high level [18]). Medical devices are under the MDD classified into the classes I, IIa, IIb, and III according to risk profile. Dependent on the degree of risk, there are variations in the stringency of assessment (Table 1). IMDs, as elaborated on in this study, belong to class III devices with the highest risk.

\section{Clinical evidence and conformity assessment process for medical devices in the EU}

"The Notified Body plays a key role in the assessment and verification of clinical evaluations provided by medical device manufacturers to support demonstration of conformity of a device with the essential requirements of the relevant Directive"[19].

The conformity assessment process (CAP) for class III devices demonstrates that a device complies with the requirements of Directive 93/42/EEC. The classification of a device dictates the appropriate CAP and conformity route [20]. In either case, manufacturers need

\begin{tabular}{|c|c|c|c|c|}
\hline Classification & Class I & Class IIa & Class IIb & Class III \\
\hline Description & $\begin{array}{l}\text { No to negligible risk } \\
\text { These devices are typically } \\
\text { simple designed and easy } \\
\text { to manufacture. Present } \\
\text { microscopic risk to the human } \\
\text { body i.e. examination gloves or } \\
\text { thermometer. }\end{array}$ & $\begin{array}{l}\text { Low risk } \\
\text { These devices include } \\
\text { short-and long-term devices } \\
\text { that represent a low risk } \\
\text { to the human body. This } \\
\text { can include catheter and } \\
\text { infusion pump }\end{array}$ & $\begin{array}{l}\text { Medium risk } \\
\text { These devices pose a relatively } \\
\text { high risk to the human body } \\
\text { i.e. respirators }\end{array}$ & $\begin{array}{l}\text { High risk } \\
\text { These devices include long-term } \\
\text { surgical invasive devices that may } \\
\text { pose a life-threatening risk to } \\
\text { patients. Examples are orthopedic } \\
\text { implants and coronary stents. }\end{array}$ \\
\hline $\begin{array}{l}\text { Premarket } \\
\text { requirements }\end{array}$ & $\begin{array}{l}\text { Manufacturers can declare } \\
\text { conformity }\end{array}$ & $\begin{array}{l}\text { Manufacturers submit } \\
\text { a dossier of literature } \\
\text { supporting claimed safety } \\
\text { and performance. Evidence } \\
\text { requirements vary by the } \\
\text { relevant NB }\end{array}$ & $\begin{array}{l}\text { Manufacturers submit } \\
\text { a record of literature } \\
\text { supporting alleged safety } \\
\text { and performance. Evidence } \\
\text { requirements vary by the } \\
\text { relevant NB }\end{array}$ & $\begin{array}{l}\text { Recommended with clinical studies, } \\
\text { but mostly non-randomized and } \\
\text { single arm studies are used to } \\
\text { demonstrate safety and performance. } \\
\text { Need conformity assessment by an } \\
\text { appropriate Notified Body }\end{array}$ \\
\hline
\end{tabular}


Citation: Groennvold WC (2017) New Regulations on Notified Bodies and Conformity Assessment of High-Risk Medical Devices in Europe: Impact on Clinical Investigation from an Industry Perspective. Int J Clin Res Trials 2: 115. doi: https://doi.org/10.15344/2456-8007/2017/115

Page 3 of 13

to provide clinical evidence for the safety and performance of a device to be granted conformity approval by a Notified Body. These shreds of evidence may include data generated through literature search, clinical experience and/or clinical investigations $[19,15]$.

Clinical investigation is defined as "a systematic investigation in one or more human subjects, undertaken to assess the safety or performance of a medical device" [21]. However, despite recommended by the European Commission's (EC) guidelines to clinical evidence, clinical investigation is not a requirement [22]. Several problems that can compromise patient safety have been identified in the European Union regulatory system [9]. There have been unacceptable high incidences of adverse clinical events and high recall rates where the regulatory framework has been portrayed as "fragmented, privatized and largely opaque; safety is dealt with in an unsatisfactory way and efficacy not at all" [15]. Moreover, time has shown that crucial areas of NBs' approach across Europe show a key weakness. The control of NBs by National Authorities depends on local voluntary approaches, not a mandatory EU standard, leading to questioning transparency, legality, and trust [8]. Further, existing legislation for CE marking focuses on safety, device quality, and performance, with no requirement for assessment of clinical efficacy. Frequently, medical devices based on existing technology rely on literature review and clinical data from equivalent products. High-risk devices based on newer technologies though, with little or no experience or devices extending intended purpose, most often require clinical investigation data $[22,19]$. Whereby, the majority of clinical investigations used as clinical evidence are non-randomized single-arm studies and rarely include sample size calculation and study hypothesis. Moreover, there is little visibility to criteria used for market approval, allowing variations in data requirements and only limited information made available by the time of approval $[16,23,22]$.

\section{Regulation Proposal}

In 2010, a huge scandal involving the company French Poly Implant Prostheses (PIP) was publicized, revealing that the silicone content of breast implants was replaced with lower grade silicon years after the original regulatory application[24]. Further BMJ and the Daily Telegraph conducted a joint undercover investigation involving submission of a fake IMD application equivalent to one used for a metal hip prosthesis that had been withdrawn from the market, the DePuy ASR. This application was submitted to test the conformity assessment processes used by 14 different NBs in five countries in Europe. These countries (Slovakia, Greece, Hungary, Check Republic and Turkey) were specifically identified for having weaknesses in the system. The investigation determined major flaws to the EU system of conformity assessments, including high price competition, a race in offering the speediest assessment, willingness to accept a low level of evidence and offers of advises to manufacturers in how to proceed to get approval $[9,15]$.

These incidents have raised concerns about the way medical devices are regulated and monitored. Critical issues have been the regulatory requirements of NBs and clinical data used for conformity assessment $[25,26]$. Moreover, they have triggered the need for a new legislation addressing identified weaknesses to existing directives. This resulted in the EC developing a proposal for a new regulatory framework in 2012, the "Proposal for a regulation of the European Parliament and of the Council on medical devices, and amending Directive 2001/83/EC, Regulation (EC) No 178/2002 and Regulation (EC) No 1223/2009“" [4]. In October 2013, the European Parliament (EP) amended and adopted parts of the proposed new regulations and recommendations, and in June 2015, the European Council published its responding proposal $(6,12,11]$.In June 2016, the consolidated version of the Medical Device Regulation was introduced [3]. The aim of aregulation change is to ensure proper health and safety protection, free movement of medical devices across country boundaries and to regain the public's trust in the parliamentary system [12].

\section{Controversial opinions}

Negotiations to the content of the regulation have been particularly complicated [27]). Applicable to the regulatory goals, the primary focus of the negotiations is the impact these changes will have on NBs, safety and protection of patients and the ability of the new regulations to increase public trust. This to safeguard that high-risk devices are only brought to the market after being sufficiently conformity assessed [28].

\section{Regulatory changes and their impact on manufacturers}

Some significant changes in the proposals are introduced in the structure and supervision of NBs where previous experiences have determined deficiencies (Table 2). Thesedeficiencies include lack of transparency in NBs' daily work, concerns about NBs' competence and their independence against manufacturers that may affect decisions to CE marking [29]. These challenges haveamongst others, resulted in that all NBs will need to apply for re-designation and be audited for compliance by joint competent authorities from several Member States [30]. The requirements of technical, clinical and scientific competence have so far resulted in suspension or closedown of several NBs. This number is estimated to increase significantly. Due to the higher demand for in-house competence for medical devices, combined with narrower business opportunities, particularly the smaller NBs are believed to be affected [31,32].

It is expected that intensified control on NBs will increase the quality of conformity assessments and reduce approvals lacking sufficient clinical evidence. This has a direct effect on manufacturers, whereby the proposed regulations require increased involvement of competent authorities when conformity assessing high-risk devices [33]. This will in turn increase costs and the duration to reach market approval and consequently, patient availability [30, 31, 34]. Coggi in Ulmann [35] states that these authorities not only add focus to safety and regulatory compliance by manufacturers and NBs, but also increase evidence requirements before receiving a CE mark. Yannakoudakis in Ulmann [35] is concerned that increased involvement of the EC, Medical Devices Coordination Group (MDCG) and Assessment Committee for Medical Devices (ACMD) will result in unnecessary bureaucracy. This might further delay medical device marketing without adding any real value to patient safety. There is also a worry that it result in fewer innovations and longer clinical investigations to gather sufficient clinical evidence. DonDiego [32] and Bartl [33] report that the additional entities involved in the review process are expected to increase patient safety and product quality. On the other side, they may add time and complexity to the CAP.

Eucomed, an organization representing the medical technology industry in Europe, questions the mentioned random sampling scrutiny process to be unable to adequately address issues to increase patient safety, ensure consistency of high-quality NBs or standardize guidelines for medical devices. This is because only a small sample of all class III medical devices applying for CE certificates will be 
Citation: Groennvold WC (2017) New Regulations on Notified Bodies and Conformity Assessment of High-Risk Medical Devices in Europe: Impact on Clinical Investigation from an Industry Perspective. Int J Clin Res Trials 2: 115. doi: https://doi.org/10.15344/2456-8007/2017/115

Page 4 of 13

\begin{tabular}{|c|c|c|}
\hline Regulatory change & Existing regulation & New regulation \\
\hline Supervision of NBs & No standard requirements & $\begin{array}{l}\text { Increased oversight and quality assurance by competent } \\
\text { authorities and MDCG/ACMD. Notified Bodies will be } \\
\text { monitored }\end{array}$ \\
\hline Scrutiny Procedure & $\begin{array}{l}\text { No conformity assessment by other regulatory authorities, only } \\
\text { performed by Notified Bodies }\end{array}$ & $\begin{array}{l}\text { MDCG and ACMD will have the ability to request } \\
\text { preliminary conformity assessment. } \\
\text { Manufacturers will be randomized to this scrutiny process. } \\
\text { This means only a few devices will go through the extended } \\
\text { conformity assessment process. }\end{array}$ \\
\hline Competence & No standard requirements of competence & $\begin{array}{l}\text { NBs expected to have permanent competent personnel and } \\
\text { technical and medical expertise in-house. } \\
\text { Competence must be documented. }\end{array}$ \\
\hline $\begin{array}{l}\text { Conformity } \\
\text { assessment process }\end{array}$ & $\begin{array}{l}\text { Heterogeneity in Notified Bodies' work. Variations in the } \\
\text { interpretation of regulations. Some more relaxed to regulatory } \\
\text { requirements when providing CE Marking. Patients are subject } \\
\text { to different safety levels. }\end{array}$ & $\begin{array}{l}\text { Standardized processes through regulation instead of } \\
\text { directives. Stronger requirements for clinical evidence. }\end{array}$ \\
\hline $\begin{array}{l}\text { Audit } \\
\text { manufacturers }\end{array}$ & $\begin{array}{l}\text { Only announced inspections, approximately every third year, } \\
\text { as well as unannounced audits. }\end{array}$ & $\begin{array}{l}\text { Subject to unannounced inspections. Inspections should be } \\
\text { annual. Unannounced audits will bring extra costs to the } \\
\text { manufacturer. }\end{array}$ \\
\hline Clinical evidence & $\begin{array}{l}\text { Evidence requirements vague. Based on ethical and } \\
\text { methodological principles. } \\
\text { Equivalence data used as evidence, based on previous studies } \\
\text { and comparative literature. } \\
\text { Safety and performance of device. }\end{array}$ & $\begin{array}{l}\text { Standardized evidence requirements. Manufacturer must } \\
\text { draw up a report on safety and performance aspects. } \\
\text { Each new device preferably requires clinical investigation } \\
\text { based on own data. Use of equivalence data requires stricter } \\
\text { evidence and criteria. } \\
\text { Justify not using randomized controlled trials } \\
\text { Performance now includes efficacy and benefit to patient }\end{array}$ \\
\hline Transparency & $\begin{array}{l}\text { Non-transparency. } \\
\text { No documents are available to the public, including data sent } \\
\text { by manufacturers for assessment, which NB that assessed } \\
\text { the pieces of clinical evidence and what the NB made their } \\
\text { decision upon. Enable companies to shop around for the less } \\
\text { strict NB and/or the cheapest, as well as to cooperate in an } \\
\text { unethical manner with NBs. }\end{array}$ & $\begin{array}{l}\text { One will have access to data submitted for approval, the } \\
\text { rationale for a NB's decision and which NB that have } \\
\text { assessed a particular medical device. } \\
\text { Clinical investigation results must be summarized and in } \\
\text { Eudamed within a year. }\end{array}$ \\
\hline
\end{tabular}

randomized to the scrutiny process. Eucomed further has worries that it will result in duplication of work in the CAP, increase red tape and wasted time on bureaucracy, and result in a false security, as most devices will bypass the MDCG and ECs' scrutiny control [36].

Traditionally, medical devices have been enabled approval based on equivalence to an already established product, in which published clinical data, commonly from different products were used as clinical evidence. With the new regulations, approval based on equivalence alone will include stricter criteria requiring more extensive clinical investigation for high-risk devices [37]. It must also be justified to apply for a CE mark without own clinical investigation [4]. This will likely increase manufacturer costs and require additional resources, patients, and time. The EP has suggested in Amendment 340 "As randomized controlled investigations usually generate a higher level of evidence for clinical efficacy and safety, the use of any other design or study has to be justified. In addition, the choice of the control intervention shall be justified. Both justifications shall be provided by independent experts with the necessary qualifications and expertise" [38]. Thomas Klein [38] however, states that randomized controlled trials might not always be ethical or feasible and should be optional, rather than a requirement likely to limit clinical investigation of medical devices.

\section{Purpose of the Study}

The research question for this study is; "What impact does the new regulatory framework on Notified Bodies and conformity assessment of high-risk medical devices have on clinical investigation from the perspective of clinical research specialists working at manufacturers of implantable medical devices in Europe?"

Despite the many papers available discussing the proposed regulations, there are few in-depth discussions about the impact a revision could have on clinical investigation of high-risk devices from manufacturers' perspective. Manufacturers' perception regarding new regulations may introduce a different view than illustrated in the literature. This perception has potential to provide additional information that traditionally is non-transparent and may further enable evaluating the impact the proposed regulations have on clinical investigation $[15,28]$.

\section{Aim and objectives}

The aim of this study is to determine the impact the proposed new regulations on NBs and conformity assessment in the EU have on clinical investigation of implantable medical devices. The objectives raised in order to answer the research question are: 
Citation: Groennvold WC (2017) New Regulations on Notified Bodies and Conformity Assessment of High-Risk Medical Devices in Europe: Impact on Clinical Investigation from an Industry Perspective. Int J Clin Res Trials 2: 115. doi: https://doi.org/10.15344/2456-8007/2017/115

Page 5 of 13

1) To assess the perspective of clinical research specialists working for manufacturers of implantable medical devices, regarding the new regulatory framework on Notified Bodies' and conformity assessments impact on clinical investigation in the European Union.

2) To identify how the new regulatory framework has an impact on clinical investigation of implantable medical devices and what parts of the clinical investigation that are impacted.

By assessing the perception of clinical research specialists (CRS) working for manufacturers of IMDs, one can identify how the regulatory changes influence clinical investigation and the aspects of the clinical investigation that are impacted. CRSs are directly involved both in the regulatory process and in the clinical investigation process and may there by contribute to highlight manufacturers' perspective. The view is outstanding, as new regulations will influence the future medical device market with, amongst others, estimated increased costs, tighter requirements for regulatory compliance and requirement of increased clinical evidence.

In this way, the study contributes to the discussion regarding the new legislations' effect on manufacturers. It may further provide conclusive evidence, as any potential impact that will be determined in this study may diverge from or support literature.

\section{Methods}

\section{Overview}

This study was designed as a quantitative survey research. A crosssectional descriptive study was carried out to investigate the impact the proposed new regulations on Notified Bodies (NBs) have on clinical investigation. The study focuses on the perspective of clinical research specialists (CRS) working for manufacturers of implantable medical devices (IMDs) in Europe. The quantitative questionnaire was designed specifically related to changes in regulations on NBs and conformity assessment that might affect clinical investigation prior to gaining CE Mark and access to the market. The purpose of the chosen methods is to address the aim and objective of this study and enable answering the research question. The underlying purpose is to add focus to the industry's view, whereas most articles on this subject focus on deficiencies to NBs and patient safety.

\section{Target population}

The target population for this study was CRSs working for manufacturers of IMDs in Europe. With the use of convenience sampling, manufacturers were identified and localized from publically available online resources. The selected companies were contacted by phone to determine the targeted CRSs and their e-mail address. The survey was then sent to the CRSs by email from the software Survey Monkey. Only one CRS per company were invited for participation. Most dedicated CRSs had the role as quality manager, development manager, director or clinical manager. All will be recognized as CRSs throughout this survey.

\section{Inclusion and exclusion criteria}

Participants were selected by the following criteria:

Inclusion criteria:

1) Clinical research specialists currently employed by European companies manufacturing implantable medical devices classified as high-risk in the EU.
2) Clinical research specialists involved in regulatory compliance to medical device approval and clinical investigation.

Exclusion criteria:

1) Clinical research specialists currently employed by European companies that do not manufacture implantable medical devices.

2) Manufacturers of in vitro devices.

3) Clinical research specialists not involved in regulations to medical device approval and clinical investigation.

All manufacturing companies that by phone appeared eligible were invited to participate. This resulted in 107 invited.

\section{Questionnaire design}

There were 15 questions in the distributed survey. The first four questions were used for study inclusion confirmation and to determine company size and knowledge level of the participants. Questions 5-14 have been divided into sections of the new regulatory framework. These regulation changes were recognized through literature review to possibly impact clinical investigation. Within each section, ten likert items were repetitive assessed in all questions 5-7 and 9-14. Additionally one likert item questioning whether all IMDs would need to be tested through clinical trials was raised in question 5 and 6 and is separately analyzed for distribution. All likert items were identified as items within clinical investigation that might be affected by the proposed regulatory changes (Table 3 ). The last question intends to obtain an overall assessment to CRSs perspective on the proposed regulatory changes.

The closed survey used fixed checkboxes for answers in the form of rating questions for participants to indicate their view. With use of likert scale, the respondents were offered five pre-coded alternatives ranging from not at all to always. It is thereby assumed that the strength is linear and that assumption attitudes can be measured. The use of a closed survey limits the amount of data that may be generated when using open-ended questions [39]. By use of multiple choices, it was feasible to filter differences associated with company size and clinical research specialists' knowledge to the proposed regulatory framework.

\begin{tabular}{|c|c|}
\hline Regulatory changes (sections) & $\begin{array}{l}\text { Potentially affected items } \\
\text { evaluated in all survey questions } \\
\text { (likert items) }\end{array}$ \\
\hline $\begin{array}{l}\text { Monitoring of Notified } \\
\text { Bodies/ scrutiny process }\end{array}$ & \multirow{5}{*}{$\begin{array}{l}\text { Number of trials } \\
\text { Costs } \\
\text { Resource requirements } \\
\text { Regulatory compliance } \\
\text { Patient safety after product } \\
\text { market entrance } \\
\text { Patient safety during clinical trial } \\
\text { Quality } \\
\text { Innovations and product } \\
\text { development } \\
\text { Evidence requirements } \\
\text { Sample size }\end{array}$} \\
\hline $\begin{array}{l}\text { Stricter requirements for } \\
\text { Notified Bodies i.e. employee } \\
\text { competence and designation } \\
\text { of Notified Bodies }\end{array}$ & \\
\hline Audit of manufacturers & \\
\hline $\begin{array}{l}\text { Cooperation between Notified } \\
\text { Bodies and manufacturers }\end{array}$ & \\
\hline $\begin{array}{l}\text { Requirements of clinical } \\
\text { evidence }\end{array}$ & \\
\hline
\end{tabular}

\section{Sample Size}

The total population was estimated to be around 150 manufacturers producing IMDs for end-users in Europe. Sample size calculations on 
Citation: Groennvold WC (2017) New Regulations on Notified Bodies and Conformity Assessment of High-Risk Medical Devices in Europe: Impact on Clinical Investigation from an Industry Perspective. Int J Clin Res Trials 2: 115. doi: https://doi.org/10.15344/2456-8007/2017/115

Page 6 of 13

small populations do not follow binomial calculation, as one would require a far smaller sample for a given accuracy[40]. Using binomial calculation with $95 \%$ confidence interval and an error rate of 5\% would demand 108 responses to reach significant data. Thisrequires an unrealistic high response rate of $72 \%$ when approaching the whole population $(\mathrm{N}=150)$.Therefore, $107 \mathrm{CRSs}$ were invited, based on the responses when collecting manufacturer information, without a goal to reach statistical significant data.

These data are analyzed with descriptive statistics aimed to summarize this sample of the population, rather than to estimate the total population. The judgment is based on considerations of the data collection tool and a risk assessment on the impact of the research outcomes. Results of these data do not represent increased risk to any parts of the population in question.

\section{Data Collection/Extraction}

Contact data from the 107 invited CRSs were collected on a Microsoft Excel spreadsheet. Invited participants were briefly informed about the content of the survey in the email sent from Survey Monkey. A button for access (link) to the survey questions was found on the bottom of the email. On the first two pages of the survey, all participants received a participant information sheet (PIS) with details about participant confidentiality and anonymity, informed consent, the student investigator, dissertation, and questionnaire. Participants that did not consent could not proceed to the survey questions.

\section{All respondents have been offered a debriefing of study results.}

\section{Data Analysis}

Collected data were analyzed with use of Microsoft Excel.All data have been exported to Microsoft Excel and de-identified by assignment of a 3-digit number.

The analyses are presented in percentages and graphical displays to demonstrate frequency distribution of answers to each question. There is also a descriptive summary of the survey's overall results. The questions have been analyzed in the pre-determined sections and to their impact on clinical investigation. This degree of impact is presented as a pie chart.

With the use of cross-tabs between equal likert scale items (i.e. costs or safety), data have been analyzed to estimate the grade of impact the proposed regulation changes have on each likert scale item. The distribution of observations is displayed using bar charts. Additionally, filters were used to determine any observed differences related to company size and CRSs' knowledge level. As these analyses only address this sample and do not generalize the findings to the population, population standard deviation and the mean has been used to calculate the distribution of answers [41].

The methods of analyses have been implemented to illustrate the impact the regulatory proposals have on clinical investigations from CRSs' perspective. Moreover, they intend to identify how the regulatory framework impacts clinical investigations by analyzing responses in the different sections, hence determine whether some have a larger impact. By examining the various likert items, determination to the proposed regulatory framework's impact on specific areas of clinical investigation was made.

\section{Limitations}

The limitations of this study may be that it only considers parts of the new regulatory framework that may influence clinical investigation. Further, the survey has been curtailed to cover manufacturers of IMD. This might reduce selection bias, as in a wider survey, some product groups would likely not be represented [42].There is also a barrier in generalizing study results due to the small sample size and use of convenience sampling. Therefore, generated data are presented to estimate this sample population and not the total population.

An unexpected cutback was that several companies due to company policy are prohibited from sharing email addresses by phone. This resulted in some invitations being sent via administrative staff, rather than directly to aCRS. This approach might have influenced response rate.

\section{Confidentiality and Ethical Considerations}

Study approval and ethical approval were obtained from the University of Liverpool prior to any data collection. The questionnaire did not collect any demographic data, and all participants were deidentified by 3-digit personal codes in Excel to assure anonymity and confidentiality of survey responses. The purpose of de-identifying data by using visible identification numbers is to maintain participant's right to withdraw, and will only be used for control purposes. This do not compromise respondent confidentiality [43].

The participating CRSs were provided a participant information sheet (PIS) that explained the study before consenting to participate. All invited participants were informed through the PIS that collected data are confidential, and that participation is voluntary. To ensure that consent was given prior to participation, participants could only access the survey after consenting. Consent was given by the participants confirming having read and understood the PIS and agreed to take part in the investigation.

The process to use email as a data collection methodology has been following parts of the CASRO's "Code of Standards and Ethics for Survey Research" where providing information by phone results in that the survey email invitees have had a reasonable expectation that they might be contacted. Moreover, the invitees have been offered the choice of being removed from future email contact [43].

\section{Results}

This chapter presents results obtained from analysis of the data collected from the survey. The analysis plan is presented in Table 4 to clarify the categorization of responses towards understanding specific areas of clinical investigation that are possibly impacted by the proposed regulatory changes. Further, the sections of the proposal were examined individually to determine impact level in clinical investigation from the perspective of clinical research specialists (CRS).

\section{Respondents}

107 respondents were initially invited to take part in the survey. Two participants opted out of the survey, and one email address was invalid. This resulted in three additional invites being sent. Two invited CRSs called to inform that they could not contribute in this 
Citation: Groennvold WC (2017) New Regulations on Notified Bodies and Conformity Assessment of High-Risk Medical Devices in Europe: Impact on Clinical Investigation from an Industry Perspective. Int J Clin Res Trials 2: 115. doi: https://doi.org/10.15344/2456-8007/2017/115

Page 7 of 13

\begin{tabular}{|l|l|}
\hline How? & What? \\
\hline Each question & Separately analyzed \\
\hline Sections: & $\begin{array}{l}\text { Questions 5-7 and 9-14 were divided } \\
\text { into five sections of proposed regulatory } \\
\text { changes and evaluated to determine if } \\
\text { there were sections more likely to impact } \\
\text { clinical investigation. }\end{array}$ \\
\hline Likert items: & $\begin{array}{l}\text { Each likert item in the likert scale from } \\
\text { questions 5-7 and 9-14 were filteredand } \\
\text { separately analyzed to determine the likert } \\
\text { item that are mostly impacted by the } \\
\text { proposed regulations. }\end{array}$ \\
\hline $\begin{array}{l}\text { Company size and } \\
\text { knowledge level }\end{array}$ & $\begin{array}{l}\text { Does it have an impact on respondent's } \\
\text { answers? }\end{array}$ \\
\hline $\begin{array}{l}\text { Overall view to } \\
\text { proposed regulation }\end{array}$ & $\begin{array}{l}\text { Are the respondents positive to the } \\
\text { regulatory proposal? }\end{array}$ \\
Table 4: Overview how results are analyzed.
\end{tabular}

survey due to only manufacturing components to medical devices. They are there by not covered by the regulatory requirement of conformity assessment by a Notified Body (NB). After sending reminders and personal emails to all invited, additionally ten email addresses were determined incorrect, despite repeated calls to obtain correct addresses. A total of 90 CRSs received the invitation to participate.

22 CRSs (24.4\%) responded to the survey.11/21 (52.4\%) completed the questionnaire, and 10/21(47.6\%) responded partially. This has led to variations in total responses to the different questions, and missing data have not been replaced. One participant did not consent.

The distribution of company size displays an overweight from which it is clear that $95 \%$ of the participants work for small- or mediumsized companies (SMEs) (Figure 1). Most participants are "little (28.6\%) or somewhat (57.1\%)" familiar with the proposed medical device regulation and $14.3 \%$ consider themselves "experts." $57.1 \%$ of the participants did also have "some knowledge" about the proposed regulatory changes for NBs, whereas $33.3 \%$ responded to have "little knowledge." Only 9.5\% considered themselves "experts."None of the respondents was unfamiliar with the regulatory proposal or changes related to NBs.

As previously stated, 95\% of the respondents are from SMEs with the main distribution to companies below 50 employees and between 100-200 employees. Therefore, only manufacturers with less than50 employees and manufacturers with 100-200 employees could be analyzed for the influence company size has on replies to the regulatory proposals impact. Further, the distribution of replies to knowledge level was concentrated on "little or some knowledge"(Figure 2). No specific pattern of distribution of responses that were related to variations in company size or knowledge level was evident.

\section{Analysis of results}

\section{Stricter requirements on NBs}

More rigorous requirements on NBs, like documentation of competence, were stated by $73.3 \%$ of the participants to "always, in most or some cases" increase costs. Further $66.7 \%$ respondents stated that it "always or in most cases" will increase need for resources, requirement of regulatory compliance and requirements for clinical evidence (Figure 3).
Most of the participants (86.7\%) believe the stricter requirements on NBs will "not at all, in a few cases or some cases" increase product quality and patient safety post marketing. $80 \%$ stated that it will "not at all, in a few cases or some cases" increase patient safety during a trial. There are diverging opinions among the participants to the grade of impact the proposed stricter requirements have on the remaining analyzed likert items.

\section{Regulations on NBs conformity assessment process}

$78.6 \%$ of all respondents stated that the new regulations on NBs' conformity assessment process would "not at all, only in few cases or in some cases" increase product quality, patient safety during trial or patient safety after market release (Figure 4 ). 64.3\% respondents stated that this part of the regulatory proposal would "always or in most cases" increase costs, and $57.1 \%$ respond that there "mostly or always" would be an increase in need for resources or requirements to regulatory compliance. $71.4 \%$ participants were of the opinion that "in most cases or always" there will be an increase in requirements for clinical evidence.

There was no clear distinction to whether the proposed changes would increase the number of clinical trials and sample size or decrease innovations and product development. There was, though, a contrasting reply observed to whether all implantable medical devices would require clinical investigation, where $50 \%$ stated "not at all or in a few cases" and 50\% "in most cases or always."

\section{Requirement of randomized controlled trials}

The majority of participants $(84.6 \%)$ answered that randomized controlled trials (RCT) and the need for justification to use any other trial design in "some cases, most cases or always" will increase costs, the need for resources, requirement of clinical evidence, trial sample size, as well as decrease innovations and product development (Figure 5). Additionally, $69.2 \%$ respond it to increase the number of trials. In contrast, most respondents are of the opinion that a requirement to use RCT to collect clinical evidence will "not at all, only in a few cases or in some cases" increase product quality $(92.3 \%)$ and patient safety during trial $(92.3 \%)$ or post marketing $(84.6 \%)$.

\section{Me-too products}

The larger percentage (76.9\%) respond that removing the ability to approve an implant based on equivalence data, would in "some cases, most cases or always" result in that fewer "me-too" products are brought to the market (Figure 6).

\section{CE-mark based on equivalence data}

All (100\%) of the participants agreed that removing the ability to gain market approval based on equivalence data to an already established product will in "some cases, most cases or always" result in increased costs, number of trials, clinical evidence and trial sample size. Moreover are $91.6 \%$ of respondents of the opinion that it would increase need of resources, requirement for regulatory compliance and decrease innovations and product development (Figure 7).

Contrary to other responses in this survey, more than half (66.7\%) state that restricting use of equivalence data as clinical evidence increases product quality and patient safety during trial, as well as that $58.3 \%$ respondents, stated it to increase post marketing patient safety. Still, 1/4give the response that removing the ability to use equivalence 
Citation: Groennvold WC (2017) New Regulations on Notified Bodies and Conformity Assessment of High-Risk Medical Devices in Europe: Impact on Clinical Investigation from an Industry Perspective. Int J Clin Res Trials 2: 115. doi: https://doi.org/10.15344/2456-8007/2017/115

Page 8 of 5

data as clinical evidence to gain CE-mark would "not at all" increase safety or quality.

\section{Notified Bodies' challenges}

More stringent requirements leading to NBs experiencing challenges like fewer designations or more expensive services, were noted in responses by $72.7 \%$ to increase costs in "most cases or always" (Figure 8). 63.6\% stated that the need for resources and number of trials would "mostly or always" increase, and 54.5\% that it would increase the requirement for regulatory compliance, requirement of clinical evidence and trial sample size.

Contrary, do $63.6 \%$ state that such challenges to NBs would "not at all or only in a few cases" increase post marketing patient safety and $54.5 \%$ respondents that product quality and patient safety during trial "not at all or only in a few cases" increase.

\section{Cooperation between NBs and manufacturers}

The major proportion of respondents answered that more stringent regulations for cooperation between NBs and manufacturers will "in most or all cases" increase the number of trials $(72.7 \%)$, costs $(81.8 \%)$, need of resources $(72.7 \%)$, requirement of regulatory compliance (63.6\%), requirement of clinical evidence $(72.7 \%)$ and trial sample size (63.3\%)(Figure 9). Further, 90.9\% respond that it in "some, most or all cases" decreases innovation and product development. Slightly more than half (54.5\%) moreover state that it will "not at all or only in few cases" increase quality and patient safety during trial or after a product receives CE-approval.

\section{Involvement of other competent authorities}

There is a broad agreement (90.9\%) among participants that the scrutiny process involving other competent authorities in the CAP will increase costs, requirement of clinical evidence and trial sample size in "some cases, most cases or always". Additionally, all participants stated an increase in the need for resources in "some, most or all cases" and $80.8 \%$ that the scrutiny process increases the number of trials and requirement of regulatory compliance. $80.8 \%$ respondents further believed that innovations and product development in "some, most or all cases" decreases.

$45.5 \%$ respondents answered that the scrutiny process does "not at all" increase patient safety during trial and after marketing a product, whereas $36.4 \%$ stated it to "not at all" increase product quality Paradoxical, 55.6\% were of the opinion that patient safety and product quality in "some cases, most cases or always" increases.

After clarifying in a follow-up question that all applications will be randomized for scrutiny, the responses were slightly different. The percentage of respondents stating that it will "not at all" increase patient safety during trial stepped up from $45 \%$ to63.6\%, as well as that $54.5 \%$ respondents found it does "not at all" increase product quality or patient safety post marketing (Figure 10).

\section{Annual audits by Notified Bodies}

$80.8 \%$ of the respondents found that annual audits by Notified Bodies would "not at all" have an impact on patient safety after a products market entrance or during trial (Figure 11). There are $45.5 \%$ responses stating that annual audits will "not at all" increase number of clinical trials or product quality; however, $80.8 \%$ of participants believe that it in "most or all cases" increases costs and $72.7 \%$ that it increases requirement of regulatory compliance. The distribution of answers to the impact annual audits have on the remaining items of clinical investigation, is widespread.

\section{Overall result -Likert items and sections}

\section{Regulatory impact on clinical investigation}

Questions 5-7 and 9-14 have been divided into the previously mentioned five sections that might impact on clinical investigation (overview in Table 3). There were 1105 replies to the ten different likert items. Patient safety during trial and post marketing, as well as product quality showed the largest amount of replies that they would "not at all" increase due to regulatory changes. The distributions of answers were therefore categorized in two groups. The three likert items to patient safety and product quality were separately evaluated in the second group to not skew the results of the proposed regulations' overall impact.

In the first group, the sections have been analyzed to determine the regulation changes that will impact clinical investigation in "some cases, most cases and always" (Figure 12). These responses were cumulatively selected 763 times. Stricter requirements to cooperation between manufacturers and NBs show to have the slightly highest impact on clinical investigation (21.8\%) followed by monitoring of NBs and scrutiny process (21.1\%), and requirement of clinical evidence (20.7\%). Stricter requirements to NBs (19.7\%) and annual audits $(16.7 \%)$ were stated to affect clinical investigation less than the other evaluated regulatory changes.

When separating the various questions inquired in the survey, it is determined that more rigorous regulations to approve a device based on equivalencies the regulation change that affect most likert items with $96.4 \%$ responding "in some cases, most cases or always". These responses indicate this regulatory change to be the one most likely to increase costs, number of trials, need of resources, requirement of regulatory compliance and clinical evidence, increase trial sample size and decrease innovations and product development as seen from the perspective of CRSs (Figure 13). Additionally, the scrutiny process of involving other authorities than NBs in the conformity assessment process is by the respondents found to have a significant impact "in some, most or all cases" (89.6\%).

The second group evaluates the distribution of replies to what regulatory change that would have the least impact on patient safety and product quality("not at all and in a few cases")(Figure 14). These responses were cumulatively selected 327 times. Within the various sections, the highest response rate $(25.5 \%)$ was that annual audit requirements most often do notincrease safety and quality. Additionally, there were frequent responses registered that enhanced requirements for competence within NBs and monitoring of NB and scrutiny process,would have little impact on increasing patient safety and quality (20.8\%).

When separating the sections into the various questions inquired in the questionnaire, NBs competence and audits are still the regulatory changes stated by $90.9 \%$ respondents to "not at all, in a few cases or some cases" increase patient safety and product quality (Figure 15). Interestingly $89.7 \%$ also state that requirements to use randomized 
Citation: Groennvold WC (2017) New Regulations on Notified Bodies and Conformity Assessment of High-Risk Medical Devices in Europe: Impact on Clinical Investigation from an Industry Perspective. Int J Clin Res Trials 2: 115. doi: https://doi.org/10.15344/2456-8007/2017/115

Page 9 of 13

controlled trials will "not at all, in a few cases or some cases" increase safety and quality. Overall $71.4-90.9 \%$ of the participants stated that product quality; patient safety during trial and after a product has entered the market will "not at all, in a few cases or in some cases" increase due to the proposed regulatory changes.

\section{Likert items -what part of clinical investigation is mostly impacted?}

1118 cumulatively selected responses to questions 5-14 were distributed over the likert scale and scaled answers. The mean of the responses is $3.2102(\mathrm{~s}=1.42983)$. When separating the likert item responses, there are 763 cumulatively selected responses in the first group with a mean of 3.57841 ( $s=1.31896) .33 .3 \%$ of all replies in this group are "always". In the second group, there are 327 answers with a mean of 2.33028 ( $\mathrm{s}=1.3157) .38 .5 \%$ of all replies in this group are that safety and product quality will "not at all" increase.

The distribution of responses to the different likert items from questions 5-7 and 9-14 is illustrated in percentage in Figure 16. Question 8 has been excluded from this evaluation, as it does not consider each likert item separately.

All nine questions were used to evaluate the likert item(s) mostly affected by the regulatory changes expanded on in this study (Figure 17). Of the total 291 responses "always", cost is the likert item most participants (18.6\%) respond to "always" increase. This distribution is followed by stricter requirements of regulatory compliance $(15.8 \%)$, increased need of resources (13.4\%), increased requirements of clinical evidence (13.4\%) and increase in trial sample size (13.1\%). Contrary, only a few participants respond the remaining items to "always" be affected.

When analyzing the 195 cumulatively selected choices that a likert item would "not at all" be impacted by the proposed regulations (Figure 18), patient safety after a product has entered the market $(26.2 \%)$ and patient safety during trial (20.5\%), as well as product quality (18\%) was most often repeated. The remaining likert items were only selected by few of the respondents to "not at all" be impacted by regulatory changes.

\section{Discussion}

This study is the first to discuss the impact the proposed new regulations for Notified Bodies (NBs) and the conformity assessment process (CAP) have on clinical investigation of implantable medical devices (IMDs) from the perspective of clinical research specialists (CRSs) in Europe. Although a limited sample of the population participated in the survey, there was a consistency of input availableas $95 \%$ of the respondents represent small-and-medium-sized enterprises (SME).

In the following, a summary of the findings will be introduced discussion of the main results and the conclusion, as well as implications, limitations and recommendations for future research.

\section{Summary of findings}

Results of this study show that parts of the proposed regulation discussed in this paper may introduce challenges to manufacturers of IMDs. The main findings of the survey that will be addressed are:
- More rigorous regulation for cooperation between NBs and manufacturers is the regulation section determined to have "the largest impact" on clinical investigation (21.7\%). This primary change is closely followed by monitoring of NBs and the scrutiny process $(21.1 \%)$, as well as regulations concerning stricter requirements for clinical evidence in the form of RCTs, equivalence data and development of me-too products (20.7\%).

- The stricter requirement for approving a device based on equivalence data has been determined to be the regulatory change having "the most impact" on clinical investigation (96.4\%).

- Requiring use of RCT or other designs with justification is appointed by $89.7 \%$ respondents to "not at all, in a few cases or some cases" increase patient safety and quality.

- Annual audits are determined to be the regulation section having overall "least impact" on clinical investigation (16.7\%).

- Audit of manufacturers and requirement of NBs competence are determined to "not at all, in a few cases or only in some instances" increase patient safety and product quality $(90.9 \%)$.

- Of all items cumulatively chosen to "always" be affected, cost is the factor most often responded to increase with $18.6 \%$ of all responses. Equal results have been determined for increased requirements of regulatory compliance $(15.8 \%)$ and need of resources (13.4\%).

- Of all items cumulatively chosen to "not at all" be affected by the regulatory proposals, patient safety after a product has entered the EU market has been found to be the likert item "increasing the least"(26.2\%). Equal results have been determined for safety $(20.5 \%)$ and product quality $(18 \%)$.

- $\quad$ Stricter requirements for cooperation have been responded by 90.9\% to decrease innovations and product development.

\section{Discussion of results}

The market for medical devices is a growing market, and it is estimated that there are more than one and a half million different medical devices [44]. Today, the European medical device industry contributes to a sustainable European healthcare system by delivering innovative, performing and safe devices. However, due to new technologies and increased expectations, the industry has recognized the necessity of improving the European Union Medical Device Directives to avoid occurrence of serious incidents like the PIP scandal. The European medical device industry is positive to a new medical device regulation, albeit there are concerns to the effect a revision will have on manufacturers in Europe [45]. In this study it is evident that there is a slight overweight in responses that the proposed regulations overall have little positive impact on clinical investigation in Europe.

\section{Clinical evidence}

One of the main regulatory changes recognized in this study to impact clinical investigation is the stricter requirement to enable device approval based on equivalence data to an existing product. $96.4 \%$ of the participants respond that costs, the number of trials, the need for resources, requirements of regulatory compliance, trial sample size and requirements of clinical evidence will increase "in some, most or all cases." Additionally innovations and product developments will decrease (91.6\%). 
Citation: Groennvold WC (2017) New Regulations on Notified Bodies and Conformity Assessment of High-Risk Medical Devices in Europe: Impact on Clinical Investigation from an Industry Perspective. Int J Clin Res Trials 2: 115. doi: https://doi.org/10.15344/2456-8007/2017/115

Page 10 of 13

The detected impact is supported by literature where industry considers the requirement of more clinical evidence overly onerous [46]. There has been opposition to the requirement of gathering data on efficacy and performance from clinical investigation despite the knowledge that a device may not work as seen in animal models or that equivalence data may not be a proof of a functioning device [46]. Moreover, there are benefits to manufacturers like timesaving, lower costs, and reduced resource demands when preparing clinical evidence on already existing data.

It is obvious that costs, requirements, and resources will increase from enhanced requirements of clinical evidence. Moreover, in agreement with the literature, more than half of the participants state that stricter requirements for clinical evidence would increase product quality $(66.7 \%)$ and patient safety both during a trial (66.7\%) and after the product has entered the market (58.3\%).For years, several entities have expressed concerns about relying on equivalence data used for pre-market approval of high-risk devices. The Faculty of Pharmaceutical Medicine of the Royal Colleges of Physicians is of the opinion that equivalence data may not tell the whole story, as there possibly are unpublished safety issues, in addition to subtle differences between devices [47]. The Centre for Evidence-Based Medicine and BMJ also have concerns about the approval of medical devices based on equivalence data, as it is not only demanding to judge the equivalence of different devices, but this procedure may be the primary driver of allowing access to poor-quality devices on the market [47]

Conversely, 25\% find it will "not at all" increase safety or quality. Further, do $89.7 \%$ of the participants support the opinion that requiring the use of RCTs, and that the choice of other designs need to be justified, will "not at all, in a few cases or only in some cases" increase patient safety and quality. It is unknown how often companies make use of this ability and whether a high use of equivalence data for approval may be the underlying reason for this study response. Up to now, the choice of using equivalence data has been with the manufacturer [19]. However, in June this year, the European Council [1] made the following statement "With regard to the first subparagraph a manufacturer can seek to justify the use of data from a demonstrated equivalent device from another manufacturer only if they have a clear contract in place with that manufacturer allowing full access to the technical documentation on an ongoing basis. The manufacturer must be able to provide clear evidence of this to the notified body, of the nature of any modification and also proof that the original clinical investigations have been performed in compliance with the requirements of this Regulation".

Due to the limited transparency of the content of clinical evidence, the proposal's impact cannot be determined. There was though an interesting contrast observed to the replies of whether all implantable medical devices would require clinical investigation. $50 \%$ respondents stated "not at all or in a few cases",and 50\% in "most cases or always." This position to the clinical investigation could indicate that some manufacturers have a routine in taking use of equivalence data for conformity assessment.

Patient safety, product quality and innovative medical devices- the overall aim of the medical device regulation

Between 71.4 and $90.9 \%$ of the respondents state that product quality and patient safety both after the product has entered the market and during a trial will rarely increase as a result of the five regulatory changes expanded on in this study. Despite literature vaguely suggesting a lack of increased safety, the responses raise concerns as observed results are in high contrast to the primary goals of the proposal published by the EC in 2012. It was here stated,", This revision aims to overcome these flaws and gaps and to strengthen further patient safety. A robust, transparent and sustainable regulatory framework should be put in place that is 'fit for purpose'. This framework should be supportive of innovation and the competitiveness of the medical device industry and should allow rapid and cost-efficient market access for innovative medical devices, to the benefit of patients and healthcare professionals" [48]. The results of this study are also a countermove to the overall agreement among stakeholders that a harmonization of rules and decisions at Member State level is needed to make certain that diverging competencies, procedures, and requirements by NBs, would not lead to approval of suboptimal products and compromise patient safety [49].

Eucomed [50] wrote in its position paper on the ECs proposal that most of the recommended measures are welcomed as they among others increase patient safety. Eucomed further specified that for patient safety to increase, one essential element that needs improvement is to "ensure that all Notified Bodies have a consistent, mandatory and transparent high level of competency and expertise for reviewing the broad range of different medical technologies"[50]. Only $10-15 \%$ of respondents were of the opinion that higher competence level would increase patient safety and product quality. It is notable that in the overall analysis to patient safety and quality, only a small percentage indicates that they will increase as a result of the proposed regulations discussed in this study (Figure 26).The benefits of regulatory improvements to raise patient safety and product quality could rarely be persuasive and might rather be overshadowed by the requisitions that potentially challenge revenue.

\section{Notified Bodies and conformity assessment- a challenging improvement}

It was determined in this study that stricter regulation for cooperation between $\mathrm{NBs}$ and manufacturers impact clinical investigation the most where for instance $82 \%$ respondents state that costs will "always or in most cases" increase. It was to be expected that the regulatory changes affecting NBs would be stated to have a large effect on multiple items of clinical investigation, both in the limitations of cooperation, but also in the supervision and designation of NBs, the annual audits, and the role of NBs in the CAPs. It is frequently discussed that tighter regulations for cooperation between manufacturers and $\mathrm{NBs}$ are needed to prevent manufacturers shopping around for best price and easier CAPs to gain CE mark [53]. This possibility has long been considered a problem that results in diverging quality of NBs work where some have been recognized to cut corners to get customers. Despite challenging safety and quality issues, it has been beneficial to manufacturers, resulting in among others lower prices, negotiable prices and disconcertingly unethical compromises to requirements of clinical evidence [53].These pitfalls have contributed to the necessity of closer cooperation between the different NBs to ensure homogenous assessments and prices. In the European Councils' proposal from 11. June 2015 it is communicated that "Manufacturers shall declare whether they have withdrawn an application to another notified body prior to the decision of that notified body or provide information about any previous application for the same type that has been refused by another notified body" [1]. 
Citation: Groennvold WC (2017) New Regulations on Notified Bodies and Conformity Assessment of High-Risk Medical Devices in Europe: Impact on Clinical Investigation from an Industry Perspective. Int J Clin Res Trials 2: 115. doi: https://doi.org/10.15344/2456-8007/2017/115

Page 11 of 13

There is already an agreement that manufacturer audit by NBs represents an important part of the stricter regulations on medical devices. The suggested annual audit for increased inspection is intended to increase product quality and patient safety. However, this approach introduces challenges to both NBs and manufacturers. It has been foreseen that competent employees might be absent, misunderstandings may occur, or circumstances related to product and production arise that influence the purpose of an audit [54] The parliament has suggested unscheduled annual audits with the intention to increase patient safety and promote quality [54]. In this study, the opposite was determined where annual inspections by NBs and requirement of medical device competence within NBs are found to be the regulatory change least likely to increase safety and quality (90.9\%). This result however, might be flawed as it is only related to clinical investigation.

Manufacturers of IMDs are reliant on NBs to gain CE mark on each product intended for the European Market. Further, it is said that particularly high-risk devices and innovations will be subject to joint assessments following the scrutiny process where other authorities like MDCG and ACMD are involved in the CAPs [55]. As a result, manufacturers will potentially experience a delay in market access, particularly considering that the Council has tightened the scrutiny process even further than was originally proposed [1]. 90.9\% of the participating CRSs found the scrutiny process to in "some, most or all cases" increase costs, requirements of regulatory compliance, the requirement of clinical evidence and trial sample size, as well as decrease innovations and product development. Moreover, the vast majority believe that product quality and patient safety will not increase. This response is in agreement with MedTech's press release on June 19. 2015,stating the opinion that the scrutiny process is superficial and do not add any value. This view was based on the fact that the requirement on NBs, the designation procedure, the oversight by national authorities and the requirements of clinical evidence have been sufficiently tightened in the Councils proposal to ensure an optimization of clinical investigation, product quality, safety documentation and CAPs [56].

\section{The price to pay or end of a story?}

The vast majority of the participants report costs to be the factor of clinical investigation that will increase the most. Moreover, there is an observed significant increase in requirement of regulatory compliance and clinical evidence, the need for resources, number of clinical trials and sample size that subsequently also result in higher expenses. This result is supported by literature where among others Eucomed and MedTech Europe conducted a survey in summer 2013 to the financial impact this revision will have on the medical device industry [50] Medical technology companies estimated for instance that for an SME to comply with the ECs scrutiny procedure it would cost an approximate of 2.5 million euro for bringing a class III product yearly to the market [50]. Rob Packard [30] further expressed concerns that increased costs following unexpected audits and the scrutiny process would add minimal benefits to manufacturers.

It has been added to knowledge that there is an overall agreement the proposal will result in substantial repercussion on the clinical investigation process and that there are several main outstanding concerns like impact on costs, innovation and product development, safety and product quality.

Manufacturers must be aware that a new MDR might result in compromising other functioning parts of the clinical investigation process. The consequences of increased costs could be fatal. There are 25000 medical technology companies in Europe. 95\% of these companies are small-or-medium-sized enterprises (SME) [51, 52]. This corresponds with the $95 \%$ respondents in this study being defined as SMEs. Often, an SME has little or no revenue, as well as frequently being innovative start-up companies. Such companies are challenged with barriers like product registration, reimbursement, procurement, and access to $\mathrm{R} \& \mathrm{D}$ incentives preventing them from developing according to potential [8].

The Council has partly recognized the need for cost awareness within the MDR. Among others, did it propose that the EC, and not the NBs as suggested by the EP, would need to carry the costs of involvement of MDCG. This will in turn prevent another cost increase to manufacturers. Another example is that micro-andsmall enterprises will not be required to have a dedicated in-house regulatory specialist [1]. Nonetheless, there is a possibility that larger companies would interpret the increase of costs and requirements differently. This could not be evaluated in this survey due to the under-representation of large-sized manufacturers.

\section{Conclusion}

The primary aim of this study was to determine the perception of manufacturers of IMDs about the impact the proposed regulatory framework on NBs and conformity assessment will have on clinical investigation. Overall, there is a consensus among all participants that the five sections of proposed regulatory changes discussed in this study, in various rates increase the number of trials, sample size, costs, requirement of clinical evidence, regulatory compliance and need of resources and decrease innovations and product development. It is also a decisive agreement that there will be fewer enhancements of patient safety and product quality in comparison to the other items considered in this study. It is alarming to realize that manufacturers of IMDs find that among the items considered in this survey, product quality and patient safety during trial or after a product enters the market, benefit the least from the proposed regulatory changes. This is even more disturbing when considering the overall aim of the revision to improve patient safety and regain public trust.

It is though not necessarily surprising. This opinion may reflect the challenges of higher costs that can be entailed when the regulation replaces existing directives. An increase in safety and product quality through regulatory improvements can only be achieved if it does not mean compromising other functioning processes. There is an economy dependent factor where increased costs in the clinical investigation process may threaten company existence, hence contribute to a propensity against implementing cost-enhancing clauses and thereby overwrite the benefits of regulatory changes to increment safety. Finally, there are ethical concerns about a redundant repetition of clinical investigation and a foreseen delay of patients' access to innovations due to i.e. the overseeing function of a scrutiny process [57].

An increase in costs might further hinder some manufacturers in marketing new products, and it is questionable whether this is the intention of a new regulatory framework. Keeping in mind that a majority of innovative companies are SMEs, it is apparent that several respondents in this survey believe innovations and product development decreases. It is though not determined what the consequences of the cost increase literally mean. The UK Parliament [46] has questioned how the Commission and Government plan 
Citation: Groennvold WC (2017) New Regulations on Notified Bodies and Conformity Assessment of High-Risk Medical Devices in Europe: Impact on Clinical Investigation from an Industry Perspective. Int J Clin Res Trials 2: 115. doi: https://doi.org/10.15344/2456-8007/2017/115

Page 12 of 13

to support SMEs if costs are rising as at present expected. To that despite these results only being representative for this survey population, they have left the author with questions to whether the proposed regulations for medical devices in the European Union will meet the goal of strengthening patient safety and allow for rapid and cost-efficient market access for innovative products. Finally, after the consolidated version being published in June 2016, a statement to financial impact should be endeavored.

\section{Limitations, implications, and recommendations for future research}

While several articles have been published to the impact of the ECs regulatory proposal and the EPs amendments, there is a gap in the literature regarding manufacturer's perception on how regulations on NBs and CAPs impact clinical investigation. This study adds to the body of knowledge and may be utilized in the further process of considering the benefits and drawbacks of the proposed regulatory framework before an acceptance of a final new MDR.

The research question asked "What impact does the new regulatory framework for Notified Bodies and conformity assessment of high-risk medical devices have on clinical investigation from the perspective of clinical research specialists from manufacturers of implantable medical devices in Europe?". In compliance with literature, this study confirmed that the implications of increased costs, resources and regulatory compliance, impact clinical investigation of IMDs. This study also displayed that the belief in increased product quality and patient safety is not as evident as the aim of the proposal indicates. Whereas some of the regulatory changes like annual audits and requirement of dedicated regulatory compliance specialists have been implemented to recommendations and requirements, the regulation still recognizes several concerns and thus warrants more work.

The study is limited by the low response rate representing $14 \%$ of the estimated total population of manufacturers in Europe. The results can therefore not be used to represent the total population. There is a chance that it would result in a different outcome. There could also not be any pattern determined to whether company size or knowledge level impact on responses, as 95\% of the participants works for SMEs. Although these responses could be interpreted to mirror the reality, it might skew the results of this study due to the underrepresentation of larger companies. There is a concern that barriers to the regulatory changes that could prevent them from reaching their potential, might influence SMEs and thereby skew the tendencies of significance the regulatory proposal has on clinical investigation.

A larger study of the population is needed to confirm the significance of the results. Moreover, the data collection tool in this study is limited to exclusively consider whether and where there is an impact. Therefore, more in-depth knowledge about the background of the replies could further advance the observations made in this study and give a broader understanding. This may include ascertaining the portability of costs to the expected increase to enable accounting for manufacturers' acceptability of risk. It may also include demonstrating motives for the small increase in patient safety and product quality and a justification of costs related to the intended increased benefit of patient safety and product quality.

\section{Competing Interests}

The authors declare that they have no competing interests.

\section{References}

1. European Council (2015) Proposal for a Regulation of the European Parliament and of the Council on medical devices and amending Directive 2001/83/EC, Regulation (EC) No 178/2002 and Regulation (EC) No 1223/2009, Council of the European Union Interinstitutional File: 2012/0266 (COD).

2. EC (2015) Towards Safer Medical Devices, European Commission Growth

3. Council of the EU (2016) Proposal for a Regulation of the European Parliament and of the Council on Medical Devices, and Amending Directive 2001/83/EC, Regulation (EC) No $178 / 2002$ and Regulation (EC) No 1223/2009, Council of the European Union Brussels June 27. 2016.

4. EC (2012) Proposal for a Regulation of the European Parliament and of the Council of Medical Devices, and Amending Directive 2001/83/ EC, Regulation (EC) No 178/2002 and Regulation (EC) No 1223/2009, European Commission 26.9.2012

5. Kramer DB (2014) Ensuring Medical Device Effectiveness and Safety: A Cross - National Comparison of Approaches to Regulation, Food and Drug Law Journal 69: 1-i.

6. Hulstaert F (2012) Pre-Market Clinical Evaluations of Innovative HighRisk Medical Devices in Europe, International Journal of Technology Assessment in Health Care 28: 278-284.

7. EUR-Lex (2013) Commission Implementing Regulation (EU) No 920/2013 of 24 September 2013 on the designation and the supervision of notified bodies under Council Directive 90/385/EEC on active implantable medical devices and Council Directive 93/42/EEC on medical devices, Official Journal of the European Union 253, 25.9.2013, p. 8-19.

8. Eucomed (2011) A New EU Regulatory Framework for Medical Devices', Eucomed Medical Technology Position Paper November 2011.

9. Cohen D (2012) Faulty Hip Implants Shows up Failings of EU Regulation', The British Medical Journal 345: e7163.

10. European Parliament (2015) Legislative Observatory Procedure File, European Parliament

11. Council of the EU (2015) Medical devices: Council getting ready for talks with EP, European Council Press release 19/6/2015.

12. EUR-Lex (2013) 2013/473/EU: Commission Recommendation of 24 September 2013 on the audits and assessments performed by notified bodies in the field of medical devices', Official Journal of the European Union 253, 25.9.2013, p. 27-35.

13. European Parliament (2014) 2012/0266(COD) - 01/12/2014 Debate in Council', European Parliament/Legislative Observatory.

14. Brosky J (2014) EU Parliament rejects PMA, but Tightens Rules', Medical Device Daily 17(206: pp. 1-9.

15. Campillo-Artero C (2013) A Full-Fledged Overhaul is needed for a Risk and Value-Based Regulation of Medical Devices in Europe. Health Policy 113: $38-44$

16. Huot L (2012) Medical Device Assessment: Scientific Evidence examined by the French National Agency for Health - a descriptive study. BMC Public Health 12(585)

17. CromSource (2015) White paper: Clinical Data for Medical Devices, CromSource.

18. EC (2015) Revision of Medical Device Directives, European Commission 10.06.2015.

19. EC (2009) Guidelines on Medical Devices- Clinical Evaluations: A Guide for Manufacturers and Notified Bodies', European Commission Enterprise and Industry Directorate General MedDev. 2.7.1 Rev.3.

20. French-Mowat E, Burnett $J$ (2012) How are medical devices regulated in the European Union?', Journal of the Royal Society of Medicine 105: S22-S28.

21. ISO (2011) ISO 14155:2011: Clinical investigation of medical devices for human subjects - Good clinical practice, ISO.

22. Tinkler J (2009) Regional Differences in Medical Device Development, Applied Clinical Trials Feb.3. 2009

23. Torjesen I (2012) UK MPs demand more stringent regulation of medical devices in Europe', British Medical Journal 345: e7350.

24. Heneghan C (2012) The Saga of Poly Implant Prosthèse breast implants', The British Medical Journal 344: e306. 
Citation: Groennvold WC (2017) New Regulations on Notified Bodies and Conformity Assessment of High-Risk Medical Devices in Europe: Impact on Clinical Investigation from an Industry Perspective. Int J Clin Res Trials 2: 115. doi: https://doi.org/10.15344/2456-8007/2017/115

Page 13 of 13

25. Parvizi N, Woods K (2014) Regulation of Medicines and Medical Devices: Contrasts and Similarities. Clinical Medicine 14: 6-12.

26. Campbell B (2013) Regulation and Safe Adoption of New Medical Devices and Procedure', British Medical Bulletin 107: 5-18.

27. Taylor N (2015) European Regulatory Roundup: The EU's Tough Road to New Device Regulations (7 May 2015)', Regulatory Affairs Professionals Society.

28. Wild C, Erdös J, Zechmeister I (2014) Contrasting Clinical Evidence for Market Authorization of Cardio-Vascular Devices in Europe and the USA: A Systematic Analysis of 10 Devices Based on Austrian Pre-Reimbursement Assessments. BioMed Central Cardiovascular Disorders 14:154.

29. Galland JP (2013) The difficulties of Regulating Markets and Risks in Europe through Notified Bodies. European Journal of Risk Regulation 3/2013.

30. Packard R (2014) What to Expect from New EU Medical Device Regulations', MDDI May 5. 2014.

31. SGS (2013) Major Changes in Medical Device CE-Certification Starts in 2014', SGS White Paper

32. DonDiego LA (2014) Embracing Change in EU Medical Device Regulation The Notified Body Perspective, Regulatory Focus March 2014 Regulatory Affairs Professionals Society.

33. Bartl T (2014) New Medical Device Regulation: Introducing Special Notified Bodies', Medical Device Plus- Regulatory Affairs and More.

34. Poos U, Edelhäuser R (2014) Focus Notified Bodies. New requirements for designation and monitoring, Bundesgesundheitsblatt Gesundheitsforschung Gesundheitsschutz 57: 1362-1367.

35. Ulmann L (2013) Clinical Trials and Medical Devices in Europe: Innovation and Harmonization, The European Files March-April 2013.

36. Eucomed (2014) The Revision of the EU Medical Devices Directives, Eucomed Medical Technology.

37. Pignot M (2012) Current status of the upcoming new medical device regulations in the EU and their impact on medical device manufacturers, Kantar Health White Paper March 2012.

38. Klein T (2014) How Will Proposed Changes to European Regulation Affect Clinical Data Requirements?', European Medical Device Technology.

39. Neutens JJ, Robinson L (2014) Research Techniques for the Health Sciences, Fifth Edition, San Francisco: Pearson Education Inc.

40. Morris E (2004) Sampling for Small Populations, University of Regina.

41. Laerd Statistics (2013) Standard Deviation, Laerd Statistics.

42. Higgins JPT, Green S (2013) Cochrane Handbook for Systematic Reviews of Interventions Chapter 8: Assessing risk of bias in included studies, The Cochrane Collaboration.

43. CASRO (2011) Code of Standards and Ethics for Survey Research. Council of American Survey Research Organizations.

44. WHO (2003) Medical Device Regulations - Global overview and guiding principles. World Health Organization.

45. Eucomed and MedTech (2014) The Revision of the EU Medical Devices Directives', Eucomed Medical Technology and MedTech Europe 1.April 2014.

46. Parliament UK (2012) Regulation of medical implants in the EU and UK Science and Technology Committee, Parliament UK.

47. House of Commons (2013) Regulation of medical implants in the EU and UK', House of Commons Science and Technology Committee Fifth Report of Session 2012-13 Volume II.

48. EUR-Lex (2012) Proposal for a Regulation of the European Parliament and of the Council on medical devices, and amending Directive 2001/83/ EC, Regulation (EC) No 178/2002 and Regulation (EC) No 1223/2009/* COM/2012/0542 final - 2012/0266 (COD) */ - Explanatory Memorandum, EUR-Lex Document 52012PC0542.
49. EPHA (2012) EPHA Position on the Proposal for a Regulation on Medical Devices, European Public Health Alliance.

50. Eucomed (2013) $€ 17.5$ billion for unnecessary measures will be a blow to medical device innovation in Europe, Eucomed Medical Technology Press Release 12. Sept. 2013.

51. MedTech (2013) The European Medical Technology Industry in Figures', MedTech Europe.

52. EUR-Lex (2003) Definition of micro, small and medium-sized enterprises', EUR-Lex Official Journal L 124 of 20.05.2003.

53. EUR-Lex (2007) Commission staff working document - Accompanying document to the Proposal for a Regulation of the European Parliament and of the Council setting out the requirements for accreditation and market surveillance relating to the marketing of products - Executive summary of the impact assessment', EUR-Lex COM (2007) 37 final SEC (2007) 173.

54. Leonard S (2014) How to Survive an Unannounced Audit', European Medical Device Technology.

55. EUR-Lex (2012) Commission Staff Working Document Impact Assessment on the Revision of the Regulatory Framework for Medical Devices. Accompanying the documents Proposals for Regulations of the European Parliament and of the Council on medical devices, and amending Directive 2001/83/EC, Regulation (EC) No 178/2002 and Regulation (EC) No $1223 / 2009$ and on in vitro diagnostic medical devices, EUR-LexDocument 52012 SC0273.

56. MedTech Europe (2015) MedTech Europe encouraged by Council discussions, MedTech Europe Press Release Brussels.

57. Eucomed (2012) Proposed Scrutiny Procedure, Eucomed Medical Technology 